Supporting Information

\title{
General Approach to the Synthesis of Heterodimers of Metal Nanoparticles through Site-Selected Protection and Growth
}

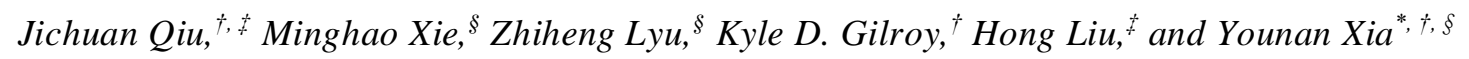

tThe Wallace H. Coulter Department of Biomedical Engineering, Georgia Institute of Technology and Emory University, Atlanta, Georgia 30332, United States

ॠState Key Laboratory of Crystal Materials, Shandong University, Jinan, Shandong 250100, P. R. China

${ }^{\S}$ School of Chemistry and Biochemistry, Georgia Institute of Technology, Atlanta, Georgia 30332, United States

"Email: younan.xia@bme.gatech.edu 
Chemicals. Trisodium citrate, ascorbic acid (AA), gold(III) chloride trihydrate $\left(\mathrm{HAuCl}_{4} \cdot 3 \mathrm{H}_{2} \mathrm{O}\right.$, $\geq 99.9 \%$ ), styrene ( $\geq 99 \%$ ), divinylbenzene (DVB, 80\%), 4-styrenesulfonic acid sodium salt hydrate, potassium persulphate $(99.99 \%)$, silver trifluoroacetate $\left(\mathrm{CF}_{3} \mathrm{COOAg}\right)$, poly(vinylpyrrolidone) (PVP, Mw 255,000$)$, palladium(II) chloride $\left(\mathrm{PdCl}_{2}\right)$, hydrochloric acid $(\mathrm{HCl}, 37 \%$ by weight in water), hexadecyltrimethylammonium bromide (CTAB, 99\%), cysteamine, potassium tetrachloroplatinate(II) $\left(\mathrm{K}_{2} \mathrm{PtCl}_{4}, 98 \%\right)$, tetrahydrofuran (THF, 99\%), potassium chloride $(\mathrm{KCl})$ potassium iodide $(\mathrm{KI})$, and iodine $\left(\mathrm{I}_{2}\right)$ were all obtained from Sigma-Aldrich and used as received. Deionized (DI) water with a resistivity of $18.2 \mathrm{M} \Omega \cdot \mathrm{cm}$ at room temperature was used in all experiments, which was prepared using a Millipore ultrapure water system (Billerica, MA). The aqueous $\mathrm{H}_{2} \mathrm{PdCl}_{4}$ solution $(10 \mathrm{mM})$ was prepared by dissolving $17.7 \mathrm{mg}$ of $\mathrm{PdCl}_{2}$ in $10 \mathrm{~mL}$ of $\mathrm{HCl}$ $(0.2 \mathrm{mM})$, followed by heating at $60{ }^{\circ} \mathrm{C}$ for $1 \mathrm{~h}$. The Au etching solution was prepared by dissolving $\mathrm{I}_{2}$ and $\mathrm{KI}$ in DI water with a molar ratio of $1: 6$. The final concentration of $\mathrm{I}_{2}$ was 0.34 mM.

Preparation of PS-Au Janus particles. We synthesized the Au nanoparticles (55 nm in diameter and covered with trisodium citrate) by following a published protocol. ${ }^{1}$ The PS-Au Janus particles were prepared by slightly modifying the protocol described in a previous publication. ${ }^{2,3}$ In a typical synthesis, $50 \mathrm{mg}$ of potassium persulphate and $6 \mathrm{mg}$ of 4-styrenesulfonic acid sodium salt hydrate were added to a $25-\mathrm{mL}$ three-neck flask containing $4.5 \mathrm{~mL}$ of water and $16.5 \mathrm{~mL}$ of ethanol. After heating the mixture to $70{ }^{\circ} \mathrm{C}, 0.2 \mathrm{~mL}$ of a styrene and DVB mixture $(200: 1, v / v)$ was introduced, followed by addition of $3.0 \mathrm{~mL}$ of the Au nanoparticles (with a total of about $1.4 \times 10^{11}$ particles) at a delay of $2 \mathrm{~min}$. The reaction was allowed to proceed at $70{ }^{\circ} \mathrm{C}$ for $1 \mathrm{~h}$. The solid products were collected via centrifugation (10,000 rpm for $10 \mathrm{~min}$ ) and washed with $60 \%$ ethanol five times. The final products were dispersed in $20 \mathrm{~mL}$ of water for further use. All the PS-Au particles involved in this work were prepared using this protocol unless notified otherwise. For the synthesis of PS-Au particles featuring a less exposed area of $\mathrm{Au}$, all the parameters were kept the same except that the DVB was used at a higher concentration, with the styrene to DVB ratio setting to 100:1 $(v / v)$.

Etching of Au from the PS-Au particles. We heated $2 \mathrm{~mL}$ of the aqueous suspension of PS-Au Janus particles to $95^{\circ} \mathrm{C}$ for $30 \mathrm{~min}$, followed by centrifugation to collect the solid particles. The 
as-obtained particles were re-dispersed in $2 \mathrm{~mL}$ of Au etching solution. After etching for $5 \mathrm{~min}$, the remaining particles were collected by centrifugation. The same etching procedure was also applied to PS-Au particles without undergoing the pre-heating process.

Synthesis of Au-Ag dimers. We mixed $2 \mathrm{~mL}$ of the aqueous suspension of PS-Au Janus particles with $2 \mathrm{~mL}$ of aqueous PVP solution $(112 \mathrm{mM})$, followed by the introduction of $2 \mathrm{~mL}$ of aqueous $\mathrm{CF}_{3} \mathrm{COOAg}$ solution $(0.31 \mathrm{mM})$. After shaking for $30 \mathrm{~min}, 0.2 \mathrm{~mL}$ of aqueous AA solution (40 $\mathrm{mM}$ ) was introduced as a reducing agent. The final concentration of $\mathrm{Ag}(\mathrm{I})$ precursor was $0.1 \mathrm{mM}$. The growth was allowed to proceed under stirring at room tem perature for $10 \mathrm{~min}$. The PS $-\mathrm{Au}-\mathrm{Ag}$ particles were collected by centrifugation and washed with water three times. Then the PS component was dissolved with a THF solution containing $100 \mathrm{mM}$ of PVP and $10 \%$ ethanol $(v / v)$. The $\mathrm{Au}-\mathrm{Ag}$ dimers were collected by centrifugation and washed with ethanol and water sequentially. To obtain $\mathrm{Au}-\mathrm{Ag}$ dimers with a reduced contact area, the PS-Au particles synthesized at a styrene to DVB ratio of 100:1 were used as the seeds for Ag deposition. All other parameters were kept the same.

Synthesis of Au-Pd dimers. We mixed $2 \mathrm{~mL}$ of the aqueous suspension of PS-Au Janus particles with $0.9 \mathrm{~mL}$ of aqueous CTAB solution $(200 \mathrm{mM})$. Then, $0.04 \mathrm{~mL}$ of aqueous $\mathrm{H}_{2} \mathrm{PdCl}_{4}$ solution $(10 \mathrm{mM})$ was introduced, followed by the quick injection of $0.04 \mathrm{~mL}$ aqueous AA solution $(12.5$ $\mathrm{mM})$. After reaction at room temperature for $1 \mathrm{~h}$, the solid products were collected by centrifugation. We obtained $\mathrm{Au}-\mathrm{Pd}$ dimers after the removal of PS component with THF.

Synthesis of Au-Pt dimers. We firstly treated $2 \mathrm{~mL}$ of the aqueous suspension of PS-Au Janus particles with cysteamine $(1 \mathrm{mM})$ at room temperature for $2 \mathrm{~h}$. After washing with water three times, the PS-Au particles were added into $2 \mathrm{~mL}$ of aqueous solution containing $220 \mathrm{mg}$ of PVP, followed by sequential introduction of $0.5 \mathrm{~mL}$ of aqueous $\mathrm{K}_{2} \mathrm{PtCl}_{4}$ solution $(1 \mathrm{mM})$ and $0.5 \mathrm{~mL}$ of aqueous AA solution $(100 \mathrm{mM})$. The reaction was allowed to proceed under ambient conditions for $12 \mathrm{~h}$. After removal of the PS component by THF, the resultant Au-Pt dimers were collected by centrifugation. 
Synthesis of Au-Au dimers. We mixed $2 \mathrm{~mL}$ of the aqueous suspension of PS-Au Janus particles with $2 \mathrm{~mL}$ of the aqueous solution containing $4 \mathrm{mM}$ of PVP and $43.5 \mu \mathrm{M}$ of $\mathrm{KCl}$. Then, $0.08 \mathrm{~mL}$ of aqueous $\mathrm{HAuCl}_{4}$ solution $(1 \mathrm{mM})$ was introduced into the above mixture, followed by the injection of $0.2 \mathrm{~mL}$ of aqueous AA solution $(25 \mathrm{mM})$. After reaction at room temperature for 30 min, the solid products were collected by centrifugation.

Computational simulation of optical properties of $\mathbf{A u}-\mathbf{A g}$ dimers. The simulations were carried out using the software package DDSCAT 7.3.00. ${ }^{4,5}$ The shape file was created using LAMMPS software. ${ }^{6}$ A model of the structure was generated by (i) creating a Ag sphere, (ii) introducing a 55-nm Au sphere with a different center to create a truncated sphere of $\mathrm{Ag}$, and then (iii) creating the $\mathrm{Au}$ sphere, which resulted in the formation of a $\mathrm{Au}-\mathrm{Ag}$ dimer. In all cases, the propagation (k-vector) and electric field (E-field) of the incident light were perpendicular and parallel to the longitudinal cross-section of the dimer, respectively. Furthermore, in all simulations, about $10^{5}$ dipoles were used to ensure accurate results. The dielectric constants of pure $\mathrm{Au}$ and $\mathrm{Ag}$ were taken from Johnson and Christy. ${ }^{7}$ Since all spectra were measured when the $\mathrm{Au}-\mathrm{Ag}$ dimers were suspended in water, the dielectric constant of the medium was taken to be $\varepsilon_{\mathrm{m}}=\mathrm{n}^{2}=1.78$.

Characterization Instrumentation. TEM studies were conducted using a JEM-1400 microscope (JEOL, Tokyo, Japan) operated at $120 \mathrm{kV}$. HAADF-STEM imaging and EDX mapping analysis were performed under Hitachi HD-2700 (JEOL, Tokyo, Japan) operated at $300 \mathrm{kV}$. The sample for TEM studies was prepared by drying a drop of the particle suspension on a copper grid coated with Formvar carbon (Ted Pella). The UV-vis spectra of the particle suspensions (in water) were obtained using a Varian Cary 50 spectrophotometer. 


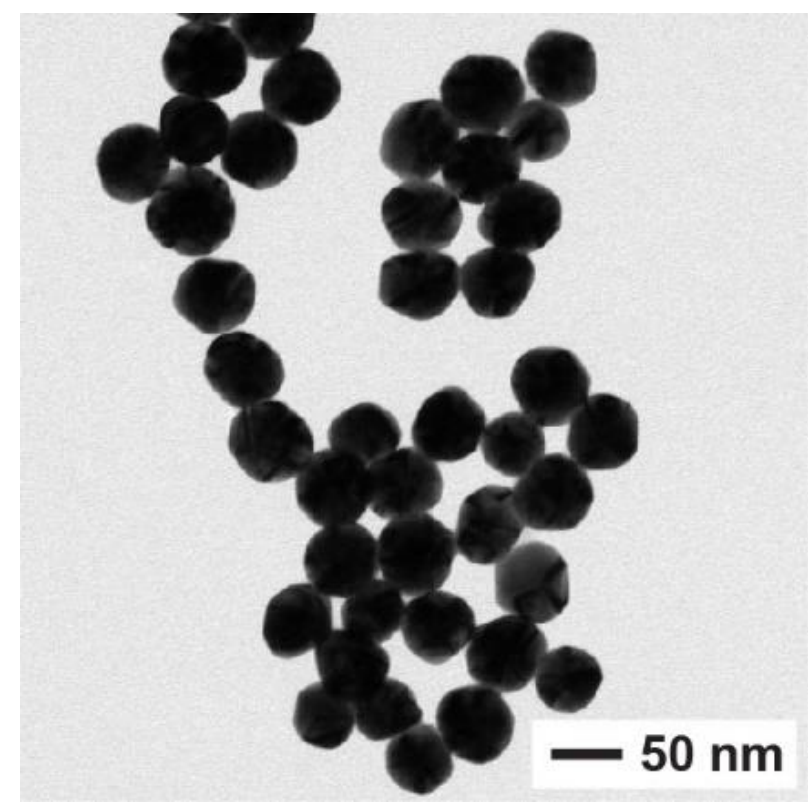

Figure S1. (A) TEM image of the Au nanoparticles whose surface were covered with trisodium citrate. 


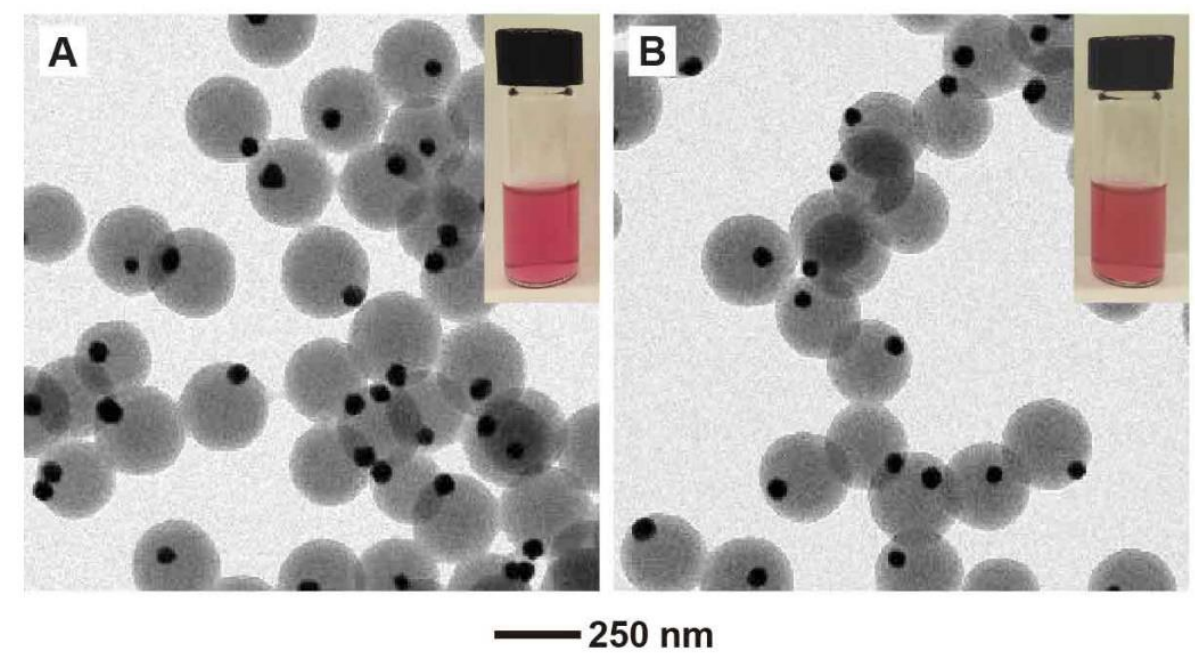

Figure S2. (A) TEM image of the PS-Au Janus particles after heating at $95{ }^{\circ} \mathrm{C}$ in water for 30 min. (B) TEM image of the heated PS-Au Janus particles after introduction into the Au etching solution for $5 \mathrm{~min}$. The insets in (A, B) show digital micrographs recorded from aqueous suspensions of the corresponding colloidal particles. 

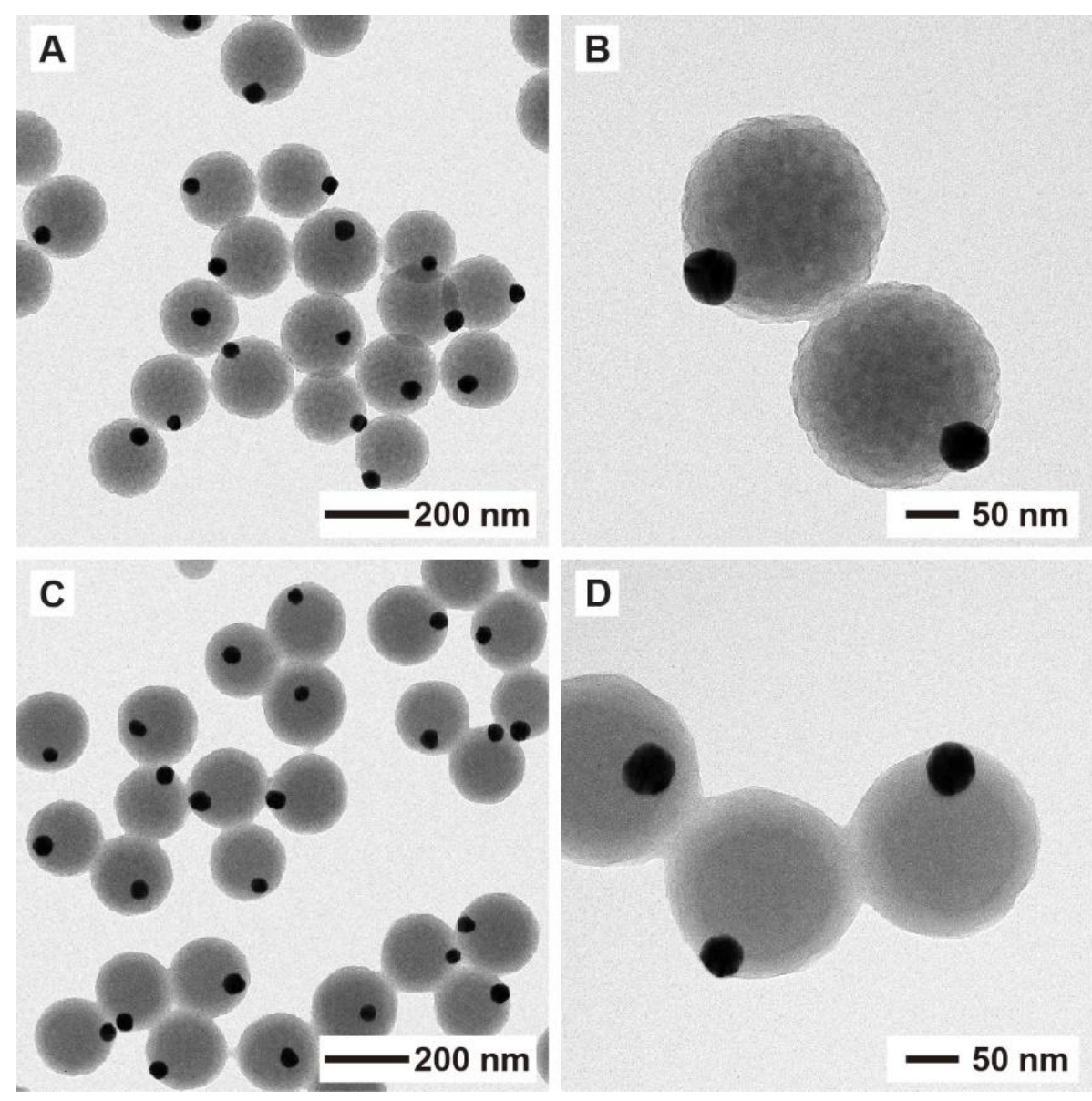

Figure S3. (A, B) TEM images, at two different magnifications, of the PS-Au Janus particles that were prepared at a styrene to DVB ratio of 200:1 (v/v). (C, D) TEM images, at two different magnifications, of the PS-Au particles that were prepared at a styrene to DVB ratio of 100:1 (v/v). 

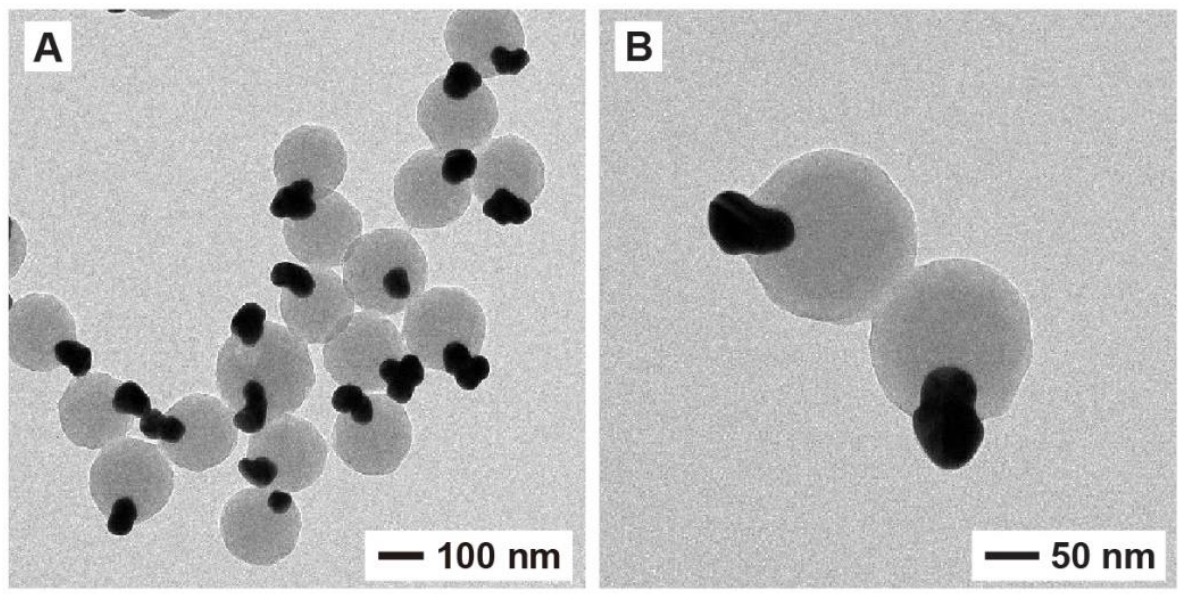

Figure S4 (A, B) TEM images, at two different magnifications, of the PS-Au-Au particles 


\section{REFERENCES}

(1) Bastús, N. G.; Comenge, J.; Puntes, V. Langmuir 2011, 27, 11098-11105.

(2) Ohnuma, A.; Cho, E. C.; Camargo, P. H; Au, L.; Ohtani, B.; Xia, Y. J. Am. Chem. Soc. 2009, $131,1352-1353$.

(3) Ohnuma, A.; Cho, E. C.; Jiang, M.; Ohtani, B.; Xia, Y. Langmuir 2009, 25, 13880-13887.

(4) Draine, B. T.; Flatau, P. J. JOSA A 1994, 11, 1491-1499.

(5) Draine, B. T.; Flatau, P. J. arXiv preprint arXiv:1202.3424 2012.

(6) Plimpton, S. J. Comput. Phys.1995, 117, 1-19.

(7) Johnson, P. B.; Christy, R. W. Phys. Rev. B 1972, 6, 4370-4379. 